\title{
METODOLOGIA BIM APLICADA NA REPRESENTAÇÃO DO EDIFÍCIO DE VALOR PATRIMONIAL
}

\author{
Alcínia Zita Sampaio \\ Universidade de Lisboa, Instituto Superior Técnico, Dep. Engenharia Civil e Arquitectura \\ Av. Rovisco Pais, Lisboa, Portugal
}

\begin{abstract}
RESUMO
Uma recente perspectiva de implementação da metodologia Building Information Modelling (BIM) é direccionada para os imóveis de valor histórico ou de relevância patrimonial, sendo designada de Historic Building Information Modelling (HBIM). Embora as ferramentas de base BIM, de uso corrente, sejam adaptadas à modelação de edifícios de arquitectura moderna, o sector da reabilitação tem vindo a apoiar a sua actividade no conceito e nas potencialidades reconhecidas da metodologia. Contudo, a questão da modelação requer uma abordagem complementar ao procedimento BIM, envolvendo técnicas de recolha de infirmação, de âmbito geométrico e histórico, modos de arquivo dos dados recolhidos, seguindo uma hierarquia temporal e cultural, e a, posterior, manipulação da informação para a actividade de conservação, manutenção ou preservação do imóvel de valor patrimonial. O texto resume a mais recente investigação direccionada para a modelação do edifício antigo, permitindo entender a complexidade da questão do registo geométrico de configurações arquitectónicas especificas de aplicação particular em cada caso concreto.
\end{abstract}

\section{PALAVRAS-CHAVE}

HBIM, Recolha de Informação, Modelação Paramétrica

\section{INTRODUÇÃO}

A metodologia Building Information Modelling (BIM) admite a capacidade de visualização do modelo tridimensional (3D) representativo do edifício, e a centralização de toda a informação associada ao seu projeto (Sacks et al., 2018). O conceito BIM considera a geração, a actualização e a reutilização de informação, centralizada num modelo digital, base do desenvolvimento do projecto colaborativo, envolvendo a participação de todos os intervenientes (Sampaio, 2017). O projeto BIM é, assim, elaborado numa base de colaboração entre todos os intervenientes da conceção do projecto, que no contexto do edifico antigo, envolve diferentes áreas técnicas, nomeadamente, arqueólogos, arquitectos, historiadores e engenheiros.

No contexto BIM, a recente pesquisa, direccionada ao imóvel de valor histórico, é referida como Historic ou Heritage Building Information Modelling (HBIM), e envolve distintos aspectos (Brumana et al., 2018):

- A metodologia de recolha de informação baseada na documentação eventualmente existente, no levantamento gráfico e fotográfico efectuado no local e na utilização de equipamento de registo de imagens digitais (laser scanner e drones);

- A tentativa de padronizar configurações arquitectónicas, com a intenção de criar objectos paramétricos representativos de formas aplicáveis e reutilizáveis na construção antiga;

- A análise de técnicas construtivas utilizadas, com o objectivo de preservar as bases metodológicas conhecidas em cada época, e de identificar os materiais empregues e propriedades físicas associadas;

- O arquivo de documentos de cadastro, estudos realizados ou intervenções prévias, e a sua disponibilização para consulta por técnicos envolvidos no desenvolvimento de futuros projectos de intervenção.

A recente perspectiva de aplicação do BIM, dirigida ao imóvel antigo, tem adquirido relevância nas áreas da preservação e reabilitação, em que é requerida uma fase inicial muito minuciosa de recolha da informação geométrica e histórica, para a obtenção de um modelo geométrico rigoroso e com conteúdos referentes a técnicas de construção ancestrais. A informação de base para o desenvolvimento das actividades de 
planeamento da reconversão ou da manutenção, deve ser recolhida, numa primeira etapa, junto a arquivos municipais, sendo posteriormente complementada com imagens digitais obtidas por diverso tipo de equipamento, nomeadamente, as tecnologias fotográficas, 3D laser sacanner e drone.

Para a representação rigorosa da forma arquitectónica e da solução construtiva adoptada no edifício antigo, as actuais bibliotecas de objectos paramétricos disponibilizadas nos sistemas de modelação de base BIM, são muito limitadas. Assim, o estabelecimento de objectos paramétricos adequados, requer uma abordagem específica quanto à representação da configuração arquitectónica marcante de cada época. $\mathrm{O}$ histórico do processo construtivo, de um imóvel que atravessou diversas tendências arquitectónicas e que acompanhou a evolução das soluções construtivas aplicadas, deve ser recolhido, estudado e arquivado, como documentação de base, na concepção do projecto de intervenção, seja com o objectivo de reparação ou de reabilitação do edifício. Os aspectos de recolha de informação e o processo de modelação, são objecto de análise no presente texto.

\section{RECOLHA DE INFORMAÇÃO}

O contexto HBIM engloba o processo inicial de estudo de contextualização histórica do imóvel, o domínio das tecnologias e materiais tradicionais aplicadas na construção antiga e o arquivo e gestão de toda a informação, recolhida e criada. Um edifício de valor patrimonial admite, normalmente, um histórico de transformações efectuadas ao longo do tempo, motivadas por diferentes influências arquitectónicas e pela alteração imposta por reconversão habitacional exigida pelos sucessivos proprietários. A informação documental, registada no cadastro do bem de valor histórico, fornece dados relevantes quanto à caracterização da construção (época histórica e sistemas construtivos) e a descrição das intervenções eventualmente realizadas. Os trabalhos de intervenção devem, contudo, respeitar o passado e o valor histórico adquirido ao longo dos séculos.

\subsection{Documentação Cadastrada}

No contexto de uma análise prévia ao imóvel alvo de intervenção, é necessário efectuar uma recolha documental e iconográfica, um levantamento gráfico e de imagens digitais, um estudo das técnicas construtivas e dos materiais aplicados, a observação de patologias na sua contextualização histórica e a avaliação do estado de conservação dirigida os elementos arquitectónicos e estruturais. Este tipo de estudo necessita que a equipa interdisciplinar possa desenvolver a sua actividade de um modo colaborativo, sobre uma plataforma de trabalho comum.

Num projecto HBIM, é relevante o nível de rigor a impor ao processo de modelação geométrica; mas, adicionalmente, é requerido que suporte a incorporação e o arquivo de parâmetros (como materiais e técnicas construtivas utilizadas, estado de conservação, etc.) e de dados de diferente natureza (como textos, documentos capturados por scanner, fotografias digitais, entre outros). A informação arquivada, num modelo centralizado e de fácil acesso, constitui um instrumento útil na gestão do património histórico, fornecendo a base documental para a análise e o desenvolvimento de projectos de intervenção. O levantamento fotográfico e fotogramétrico, o mapeamento de danos e a análise estratigráfica, com vista à análise do actual estado de conservação do imóvel, constituem um complemento à base de dados para a criação do modelo HBIM. O arquivo da informação do construído permite estruturar o cadastro do imóvel, constituído por toda a informação recolhida e criada, apoiando o estudo de futuras intervenções.

\subsection{Informação Digital}

A gestão do património arquitectónico, por recurso a tecnologias digitais, torna o processo de arquivo da documentação, manutenção e actualização mais ágil, completa e acessível, constituindo um benefício importante na preservação do edifício de valor arquitectónico:

- O levantamento fotogramétrico consiste na obtenção de fotografias, segundo distinto ponto de vista, e da aplicação de algoritmos de remoção, das imagens, o efeito de perspectiva. As projecções são ajustadas à escala, de forma a permitirem uma correcta obtenção de dimensões. No âmbito HBIM, 
este processo é utilizado para atingir um elevado nível de detalhe para que a reprodução, dos componentes construtivos ou detalhe decorativos, em termos de objectos paramétricos, possa ser rigorosa;

- A tecnologia 3D laser scanner detecta, com uma elevada precisão e com uma rápida taxa de aquisição (milhões de pontos por segundo), a configuração de fachadas e paredes interiores, na forma de uma nuvem de pontos, associados a coordenadas $(x, y, z) \mathrm{e}$, eventualmente, à intensidade de cor (red, green, blue, $R G B$ ). Num estudo recente, dirigido à caracterização anti-sísmica do Palácio Nacional de Sintra, e de forma a obter a sua correcta geometria, foi estabelecida uma campanha de recolha topográfica com estações de dispositivos laser, localizadas pelo interior e exterior do edifício (Ponte et al., 2019). Com base nos dados da nuvem de pontos, obtida com o equipamento laser e ainda com um drone, e por inspecção visual do local, foi criado o respectivo modelo BIM (Figura 1).
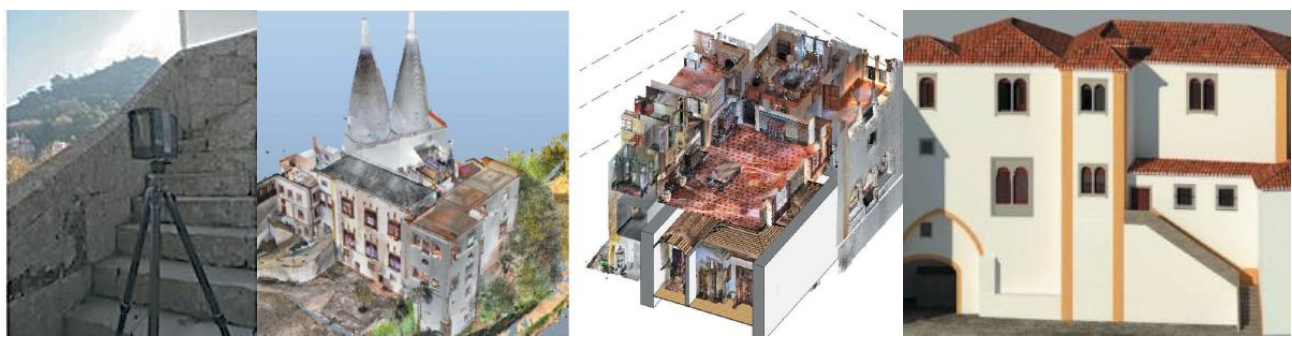

Figura 1. Equipamento (laser scanner 3D e drone), nuvem de pontos e modelo BIM

- Uma instalação laser foi, igualmente, utilizada no projecto de recuperação arquitectónica do mercado Giulio Romano (2018) em Mântua, Itália, onde foi adoptada a abordagem HBIM, abrangendo as fases de projecto e de planeamento dos trabalhos de restauro. As ferramentas de modelação BIM, de uso frequente, suportam a importação de nuvens de pontos, permitindo a representação de sistemas de construção, incluindo alvenaria, colunas, arcos e abóbodas. No entanto, o processo de identificação de objectos paramétricos é complexo e moroso. A modelação HBIM envolveu a representação rigorosa dos elementos de tijolo e a atribuição diferenciada de material, estado de degradação e fase histórica (Figura 2). Como informação complementar foram obtidas fotografias e estudadas as técnicas construtivas aplicadas à época.

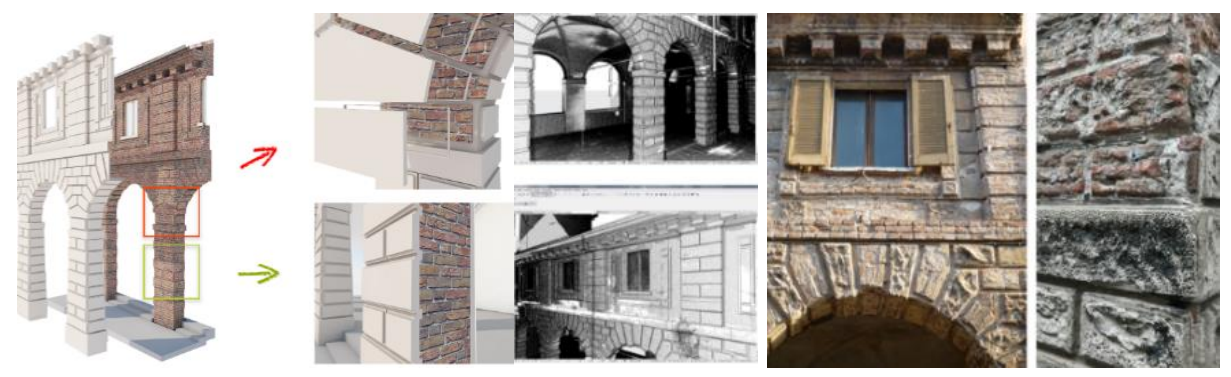

Figura 2. Mercado Giulio Romano em Mântua, Itália

- O monumento histórico é, normalmente, constituído pela sobreposição de tipos de construção efectuados em intervenções de remodelação, que se sucedem no tempo, os quais são registados por testemunhos de distinto material ou identificação arquitectónica de época. A análise estratigráfica abrange o estudo das acções construtivas e destrutivas num edifício e a etapas construtivas são representadas por diferentes cores, conduzindo a uma percepção visual da cronologia construtiva, apoiando a análise das soluções arquitectónicas aplicadas (Genovez, S.C., 2012). Em relação ao palácio de Sintra, foi efectuada uma análise documental histórica, a qual foi aplicada sob o modelo BIM criado, ilustrando as distinta intervenção de remodelação, percorrendo o período árabe, os reinados de D. Dinis a D. Manuel I e o século XVII, sendo possível obter um modelo estratigráfico (Figura 3). 


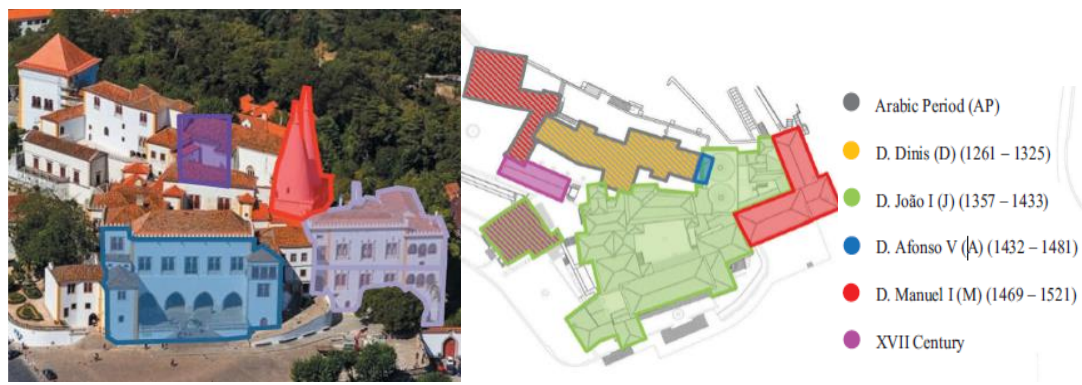

Figura 3. Representação de análise estratigráfica relativa ao Palácio Nacional, em Sintra

No contexto HBIM, as famílias de objectos que compõem o modelo virtual, podem ser associadas a parâmetros relativos a cada época histórica de cada remodelação construtiva, as quais podem ser apresentadas com uma coloração distinta.

\subsection{Hierarquia de Informação}

No conceito HBIM o modelo BIM pode ser criado de forma a incorporar parâmetros com distinto tipo de informação, organizados por etapas históricas de construção, e arquivados como camadas de dados devidamente datados, formando uma sequência hierárquica e cronológica de informação. Este modelo é designado de modelo as-built, em que o modelo é composto por diversas "idades" de informação, promovendo a consulta da informação heterogénea relacionada com a edificação antiga.

A igreja de Santiago de Penalva, do século X, localizada na província de Castilla y León, Espanha, de arquitectura mozárabe-hispânica, foi registada, em 1931, na Dirección General de Patrimonio Cultural, como um Monumento Histórico-Artístico Nacional (Murillo, 2017). Este organismo solicitou um trabalho de reorganização de informação, de forma a complementar a documentação cadastrada existente, englobando: a contextualização histórica e artística do monumento; as intervenções recentes de restauração, eventualmente, efectuadas; a análise do actual estado de conservação de paredes e elementos decorativos do edifício (Figura 4). A documentação, organizada segundo a hierarquia as-built e em suporte digital, fica acessível para consulta por técnicos, podendo ser filtrada de acordo com os parâmetros relativos a épocas construtivas, como base de análise de estudos de preservação, de restauro ou como apoio à gestão do próprio monumento.

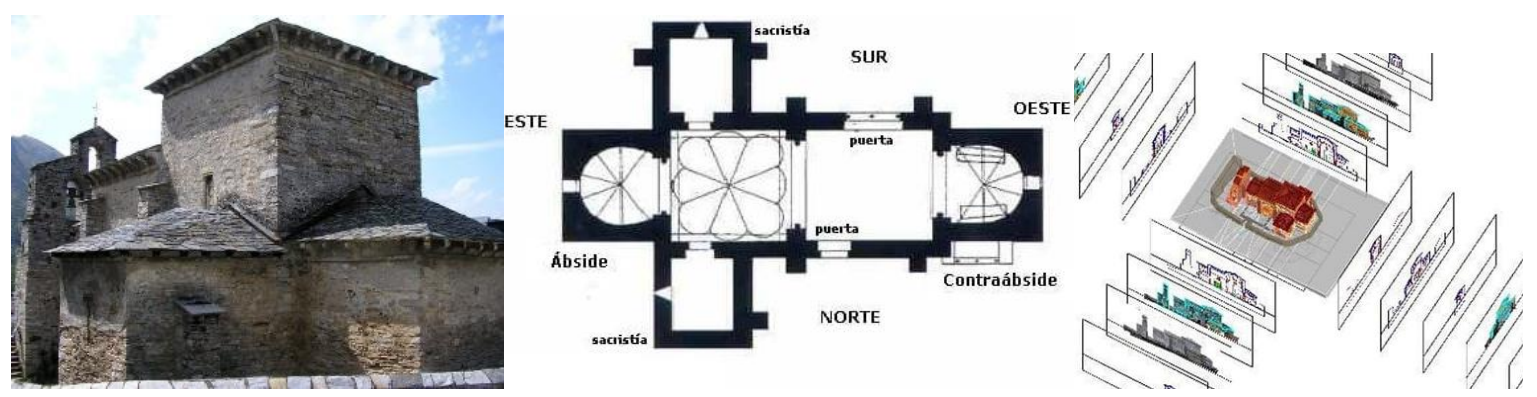

Figura 4. Igreja de Santiago de Penalva: fotografias, planta e modelo BIM as-built

\section{PADRONIZAÇÃO E MODELAÇÃO}

A concepção de objectos paramétricos representativos de elementos arquitectónicos, incluindo o leque de ornamentos associado, normalmente não tipificados e únicos em cada obra, pode, em parte, ser baseado na interpretação de manuscritos sob arquitectura, pois o processo de modelação rigorosa num projecto HBIM requer uma representação sustentada no estudo da história de arte. 


\subsection{Identificação de Regras Geométricas}

Segundo Murphy et al. (2013) o conceito HBIM constitui uma direcção inovadora do BIM onde a interactividade com o objecto paramétrico, deve permitir representar correctamente os elementos arquitectónicos, tanto em forma como no material constituinte. A construção de uma biblioteca paramétrica de elementos arquitectónicos requer um estudo detalhado sobre técnicas de construção, as quais podem ser encontradas em manuscritos sobre arquitectura, enquadradas em cada época. A evolução histórica dos manuscritos, seguindo uma ordem cronológica, permite a identificação de regras características da ornamentação aplicada nos edifícios clássicos, as quais devem poder ser representadas na modelação computacional, através de famílias especificas de objectos.

Os padrões aplicados na construção antiga, seguem normalmente regras de definição que estão devidamente documentadas e ilustradas. Ou seja, é relativamente fácil identificar formas de revolução geradas com base em regras paramétricas da geometria de formas, características, por exemplo, de uma base de pilar, do seu fuste ou capitel ou de portais em arco e, ainda, de coberturas de configuração cilíndrica ou esférica (Figura 5). No contexto HBIM, o estudo relativo à recolha de informação e à caracterização de regras de geração de formas, tem como objectivo, a concepção de bibliotecas de objectos por época e tipo de construção, aristocrática, religiosa ou institucional (Quattrini et al., 2015).
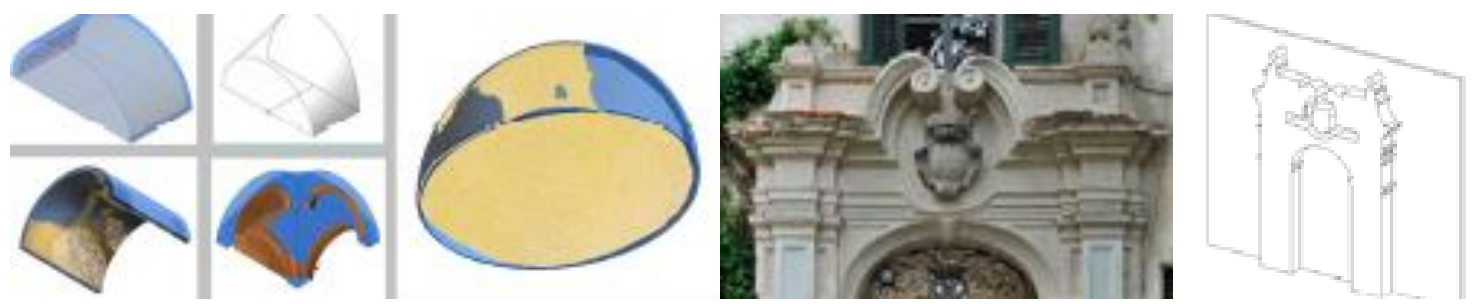

Figura 5. Formas geométricas como base de objectos paramétricos

A tradução da complexidade da construção histórica através de um modelo 3D, por recurso a ferramentas que incorporam algoritmos reguladores rígidos, característica subjacente à modelação paramétrica dos instrumentos computacionais disponíveis, constitui uma limitação à obtenção de uma réplica da realidade, o que contrasta com a variabilidade e especificidades da construção histórica. Ramalho (2011) efectua uma análise ao grau de degradação dos elementos escultóricos e decorativos que compõem o portal principal da Sé do Porto.

A configuração dos elementos decorativos é representativa da construção religiosa, do início do séc. XII. A geometria é analisada com o objectivo de estudar os padrões aplicados, de forma a identificada a sua geometria exacta, traduzida por leis de geometria analítica referente a arcos circulares e elípticos e por curvas paramétricas de evolução (Figura 6). Neste sentido os sistemas de modelação BIM admitem capacidades suficientes à sua representação, de um modo idêntico aos sistemas computacionais de traçado de desenhos.

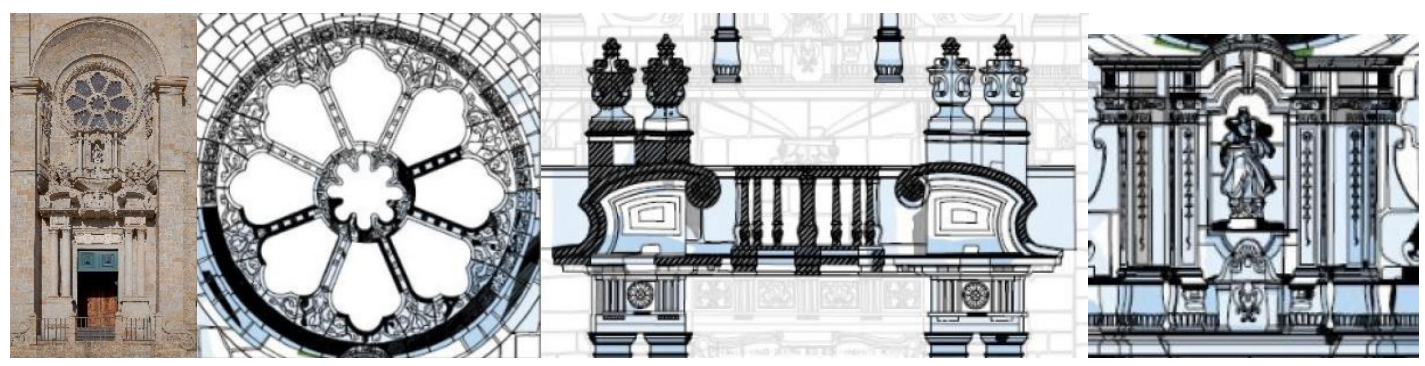

Figura 6. Identificação de formas geométricas

\subsection{Famílias Paramétricas Específicas}

O estudo de reabilitação estrutural de um edifício, na zona nobre da cidade Lisboa, proposto por M. Pinto (2020), iniciou com a recolha documental, solicitada ao Arquivo Municipal de Lisboa, composta por desenhos de plantas, alçados e corte, datados de 1924, e pelo registo das alterações efectuadas (amarelos e 
vermelhos), referido ao ano de 1953. Com o objectivo de gerar os objectos representativos dos elementos de vão e adornos existentes na actual construção, foi, adicionalmente, efectuado no local, um levantamento gráfico (esquiços) e fotográfico e, ainda, uma inspecção ao estado de conservação dos componentes do edifício, nomeadamente, aos elementos resistentes e aos revestimentos de pavimentos e paredes (Figura 7).

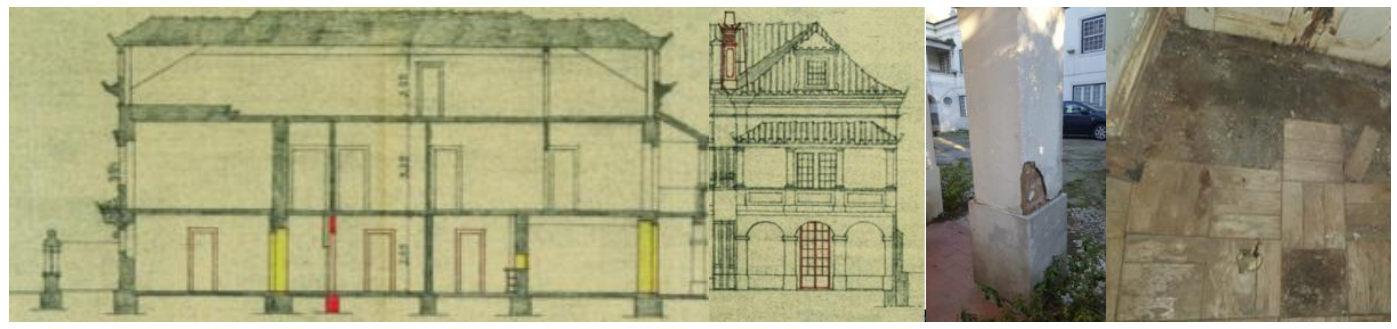

Figura 7. Documentos de arquivo e fotografias

No estudo de reconversão habitacional proposto por M. Pinto (2019), referente a um palácio do início do séc. XX, foi criada uma biblioteca de famílias específicas, requerido no processo rigoroso de modelação. $\mathrm{O}$ imóvel de valor patrimonial apresenta características idênticas a outros edifícios da cidade de Lisboa, que marcam a construção nobiliária à época. A biblioteca do software utilizado não admite a representação rigorosa de elementos de vão, com o detalhe exigido. Contudo, por recurso à capacidade de geração de famílias de objectos, inerente ao software, foi definido um conjunto de famílias específicas.

A ferramenta BIM utilizada admite a geração de famílias específicas e o seu arquivo de modo a estabelecer uma biblioteca reutilizável na modelação de edifícios de idêntica tipologia e época. O processo requer um dispêndio relevante de tempo de modelação. O sistema de modelação BIM utilizado, o Revit (Autodesk), apresenta uma biblioteca de janelas de edifícios comuns e de corrimões, contudo, a janela de guilhotina e as balaustradas, que se pretendem representar, apresenta diferenças de tipologia e de detalhe.

A metodologia do processo construtivo da janela de guilhotina é baseada em quatro etapas: (1) definição da abertura de vão com as dimensões recolhidas no local; (2) modelação dos elementos envolventes de apoio à colocação da janela (ombreira e peitoril); (3) geração dos dois painéis que compõem a janela; (4) criação dos adornos exteriores de cantaria.

1. Na interface inicial da ferramenta BIM é selecionada a opção de arquitectura e é indicada a criação de uma nova família de janelas. A definição de uma janela requer uma parede de suporte, a qual deve ser adaptada à espessura pretendida e à abertura do vão. Sob a janela, a espessura da parede de fachada é reduzida, de acordo com o esquiço traçado no local (Figura 8). A forma geométrica lateral e superior, em bisel, é definida através de uma operação de extrusão seguida de extração.
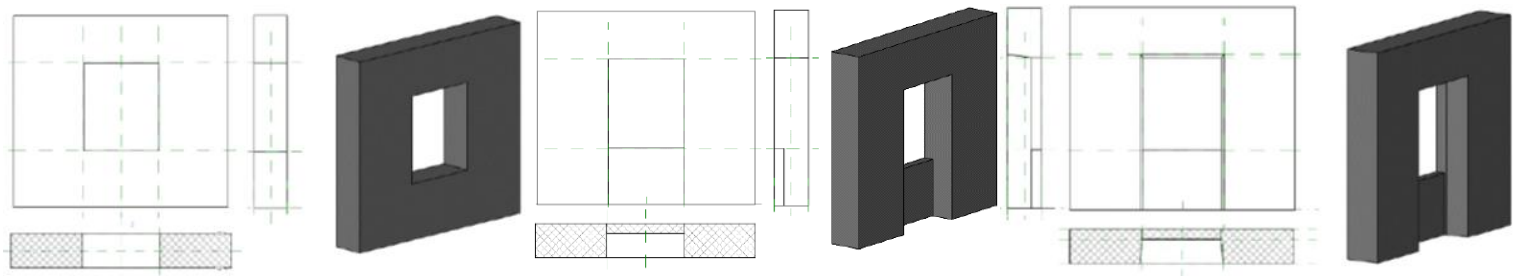

Figura 8. Geração da abertura da janela

2. Criada a abertura, é definida a zona envolvente de colocação da janela, sendo a modelação assente na interpretação de esboços definidos no local, com o detalhe e as dimensões necessárias (Figura 9). A inserção de uma cantaria (ombreira e peitoril) em granito, envolvendo o vão da janela, foi efectuada através das opções de extrusão e de varrimento; 

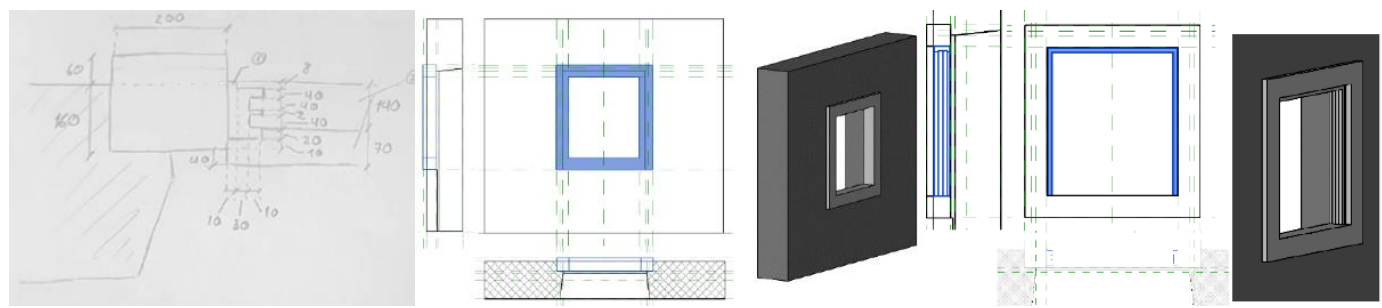

Figura 9. Modelação dos elementos envolventes, ombreira e peitoril

3. Finalmente, são gerados os dois painéis que compõem a janela. O esquiço, traçado no local, apresenta detalhes geométricos precisos relativos à composição dos elementos de contorno e da partição interna, envolvendo as placas de vidro (Figura 10).

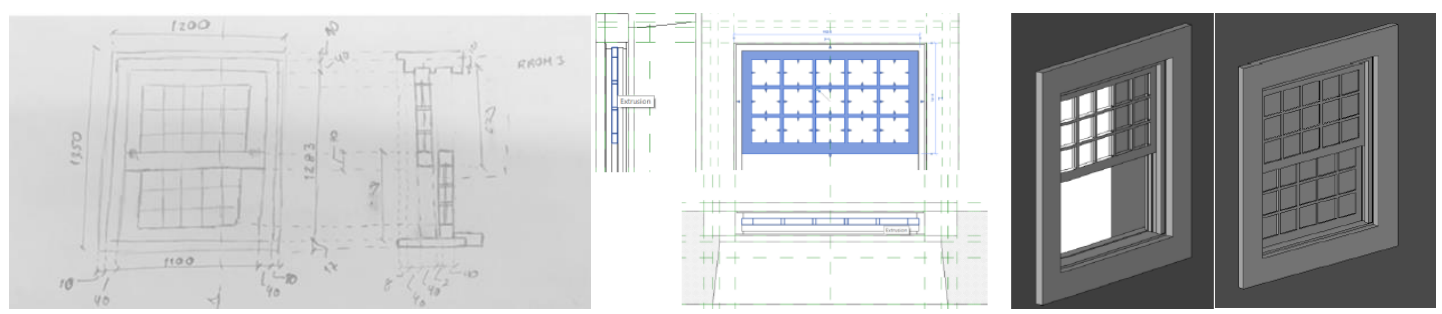

Figura 10. Modelação dos painéis da janela

4. Os painéis são idênticos e estão colocados em paralelo, mas de forma a deslizarem, lateralmente, sobre os detalhes dos elementos envolventes já modelados. Assim, a definição da geometria dos aros de contorno, é apoiada nas formas detalhadas já estabelecidas, por recurso ao comando de extrusão. Os painéis da janela ficam encaixados sobre a superfície do peitoril e nas reentrâncias dos elementos laterais. Os elementos de vidros são colocados nas aberturas da esquadria da janela. Como os painéis são idênticos, é efectuada uma cópia, da esquadria e dos vidros, e indicado o posicionamento adequado do painel inferior.

$\mathrm{Na}$ fachada frontal, a janela de guilhotina, posicionada sobre a porta principal, apresenta elementos decorativos em cantaria, envolvendo o vão, compostos por placa inferior, pinocos laterais, frontão e outros detalhes (Figura 11). A geração de cada elemento requer o estabelecimento de um processo de modelação distinto.
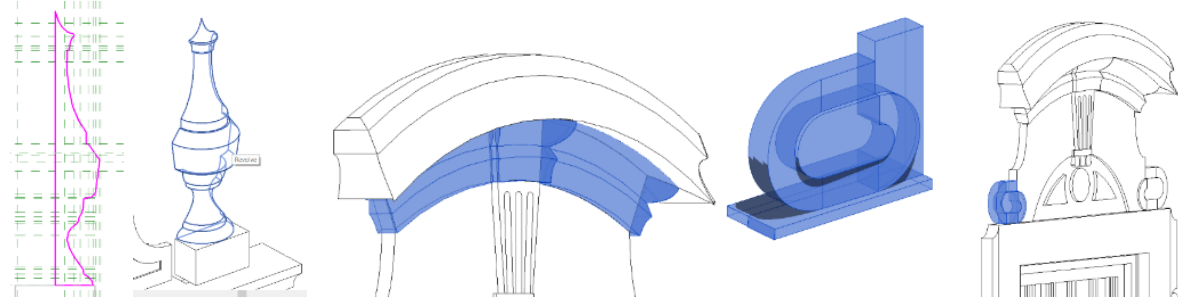

Figura 11. Modelação de elementos decorativos, em cantaria, em torno da janela

A janela completa, com a abertura correctamente executada na parede, a armação e o peitoril definidos com muito rigor, o processo de modelação dos dois painéis da janela devidamente efectuado e, ainda, estabelecida a colocação de um conjunto de elementos de ornamentação em cantaria, fica finalmente gerada. As restantes janelas em guilhotina embora semelhantes apresentam alguns pormenores distintos, requerendo uma adaptação adequada. Os restantes elementos de vão, como as portas, requerem idêntico desenvolvimento e, portanto, uma morosidade acrescida, quando comparado com a uma modelação de construção moderna (Figura 12). Outros elementos foram criados de forma a poder gerar um modelo BIM representativo do palácio em estudo.

A modelação da arquitectura do edifício de interesse histórico, por recurso a uma ferramenta de modelação BIM, requer uma pormenorização geométrica muito detalhada, um treino das capacidades tecnológicas avançadas disponíveis no sistema utilizado, o conhecimento do modo de arquivar e reutilizar as famílias de objectos específicos criados, para aplicação no mesmo imóvel ou, eventualmente, noutro edifício da mesma época de construção, sujeitas naturalmente a adaptações. 

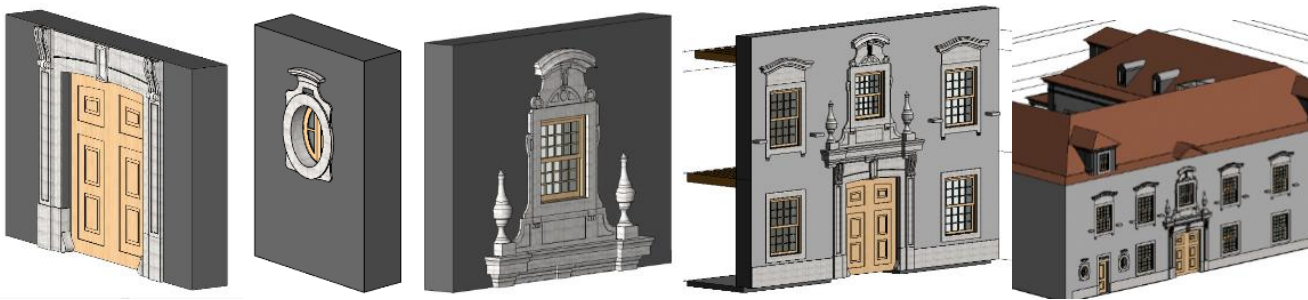

Figura 12. Famílias de objectos paramétricos de janelas e portas e inserção no modelo do palácio

\section{CONCLUSÕES}

A estudo de intervenção de um edifício de interesse histórico pode, actualmente, ser baseados na metodologia BIM. Para a definição rigorosa da arquitectura do edifico é necessário, previamente, recolher informação cadastrada e digital, obtida por equipamento fotográfico, scanner, drone e, ainda, o conhecimento relativo à sua construção (estratigrafia). Com base na informação necessária, o utilizador de uma ferramenta de base BIM de uso comum, deve proceder ao desenvolvimento das objectos paramétrica pretendidas, por recurso às funcionalidades relacionadas com a geração de famílias. A modelação de um edifício com características específicas, de difícil geração a partir das bibliotecas disponíveis, nas ferramentas de uso frequente, exige um consumo inicial de recolha de informação, de traçado minucioso de detalhes e do entendimento suficiente de manipulação de ferramentas de modelação BIM, de forma criar uma biblioteca útil. O conceito HBIM tem-se revelado um tópico bastante interessante de investigação e de aplicação em casos reais de reabilitação, reconversão ou de conservação.

\section{REFERÊNCIAS}

Brumana, R., Torre, S. D., Previtali, M., Barazzetti, 1., Cantini, 1., Oreni, D., Banfi, F., 2018 Generative HBIM modelling to embody complexity (LOD, LOG, LOA, LOI): surveying, preservation, site intervention-the Basilica di Collemaggio (L'Aquila), Applied Geomatics.

Genovez, S.C., 2012, Análise estratigráfica: uma contribuição ao projeto de restauro, Dissertação de Mestrado em História e Fundamentos da Arquitetura e do Urbanismo, São Paulo, Brasil.

Murillo, J.I., 2017, Secuencia constructiva de la iglesia de Santiago en Peñalba de Santiago (Ponferrada, León). Reformas de un edificio unitario. Arqueología y Territorio Medieval. $\mathrm{N}^{\circ} 24$.

Murphy M., MCgovern E., Pavia S., 2013, Historic Building Information Modelling: Adding intelligence to laser and image based surveys of European classical architecture, ISPRS - Journal of Photogrammetry and Remote Sensing 76 (2013) 89-102.

Pinto, A. M., 2020, O projecto de estruturas em BIM: reconversão de edifício de valor patrimonial. Dissertação de Mestrado Integrado em Engenharia Civil, IST, Lisboa, Portugal.

Ponte, M., Bento, R., Vaz, D., 2019, A multi-disciplinary approach to the seismic assessment of the National Palace of Sintra, International Journal of Architectural Heritage.

Quattrini, R., Malinverni, E.S., Clini P., Nespeca R., Orlietti, E., 2015, From TLS to HBIM. High quality semanticallyaware $3 D$ modeling of complex architecture, The International Archives of the Photogrammetry, Remote Sensing and Spatial Information Sciences, Avila, Spain.

Ramalho, M.M., 2011, Building Archeology and surveying methodologies tradition cannot be what it was, III International Seminary ArcHC_3D, Lisbon, Portugal.

Romano Giulio, 2018, Pescherie di Levante https://www.bimportale.com/la-traduzione-della-complessita-del-costruitostorico-nel-modello-hbim/

Sacks, R., Eastman, C.M., Teicholz, P., Lee, G., 2018, BIM handbook: A guide to Building Information Modeling for owners, designers, engineers, contractors, and facility managers, $3^{\text {rd }}$ ed., ISBN: 978-1-119-28755, 2018, 688 pgs Copyright (C) 2018 by John Wiley \& Sons, Inc.

Sampaio, A.Z., 2017, BIM as a Computer-Aided Design methodology in Civil Engineering, JSEA - The Journal of Software Engineering and Applications, ISSN: 1945-3124 (online), $\mathrm{n}^{\mathrm{o}}$ 10, pp. 194-210, https://doi.org/10.4236/jsea.2017.102012. 